\title{
THE ENIGMA OF PAIN
}

The unusual subject of pain in all its forms is explored at a recently opened Wellcome Trust exhibition at the Science Museum in London. Arveen Bajaj speaks to the exhibition's curator, Javier Moscoso, about the themes, ideas and insights behind the exhibition.

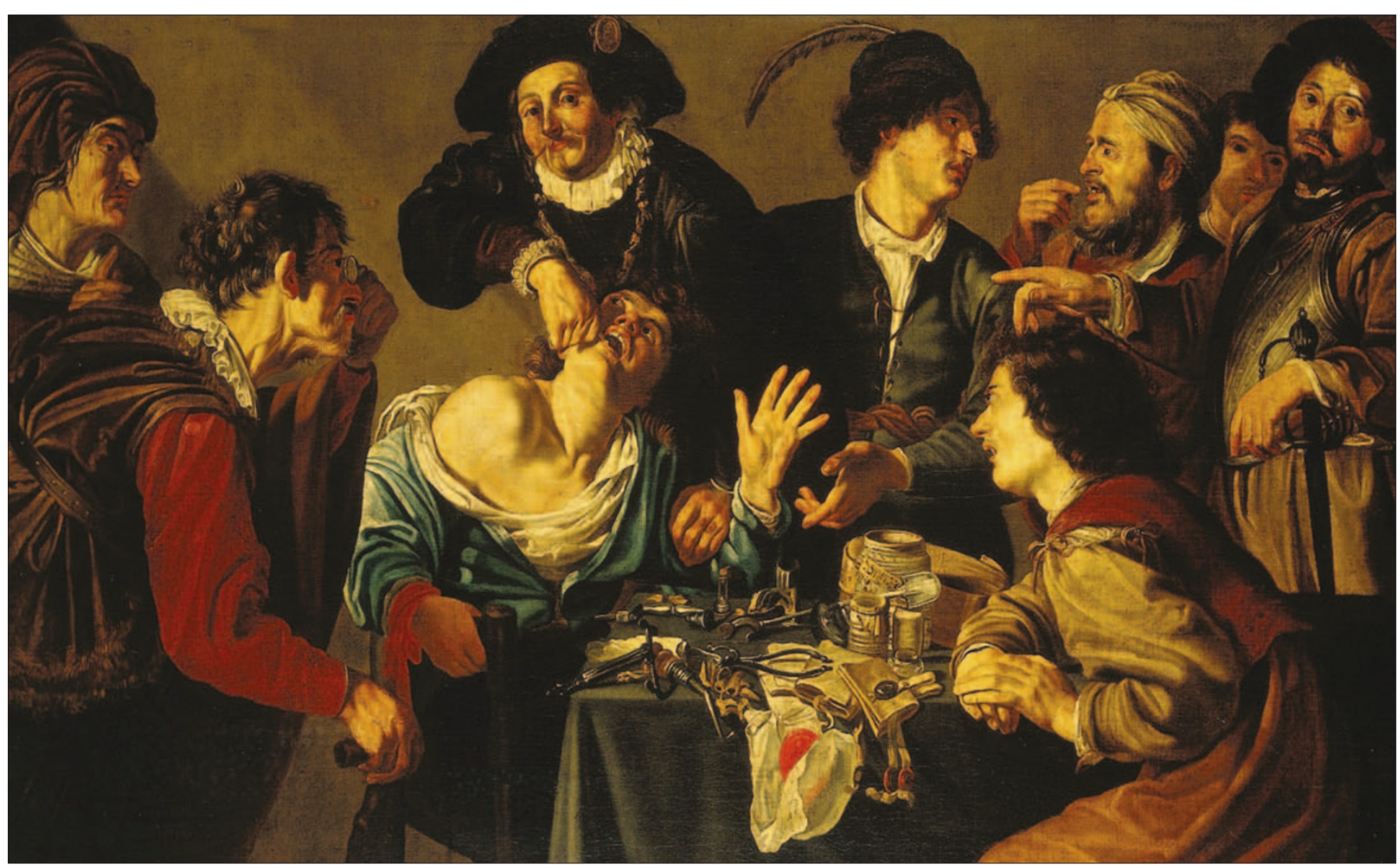

An operator extracting a tooth, unidentified painter, after Theodor Rombouts (1597-1637)

To Spanish philosopher Javier Moscoso, curator of the exhibition Pain: Passion, Compassion, Sensibility, the subject of pain is both a difficult one and one that imbues many different possibilities.

In the exhibition, he uses his native Spain as a cultural reference point for an examination of the enigma of pain through a series of exhibits. The pain of amputation, childbirth, torture, masochism and of course dentistry are just some that are explored through both historical and contemporary exhibits.

The exhibits include curios from the original collections of Sir Henry Wellcome such as a Victorian head perforator, 18th century dental forceps and a 15th century choke pear and thumbscrew. Together with items from the Science Museum collections, the exhibition also looks at how scientists have contributed to our understanding of the science of pain.
The exhibition also features a selection of paintings, drawings and objects relating to dentistry both contemporary and historical.

One of the larger pieces in the exhibition is the painting entitled 'An operator extracting a tooth' by an unidentified painter (pictured above).

\section{Its basis is the correlation}

\section{between science, history}

\section{and art}

"I think this picture is not only a general introduction to the subject of dentistry but also to the subject of pain itself." Javier observes. "It has all the elements of the exhibition in it. We have the private pain of the individual having their tooth extracted, then the public gaze, as it is a scene in which everyone is looking at something central which is the pain of another and finally we have the scientific and technical co-operation which in this case is dentistry and it is also an artistic piece." Javier believes that it depicts the correlation between science, history and art - the themes upon which the exhibition is based.

He also has some interesting insights into another piece featured in the exhibition, 'A scientist using a steam machine with pulley to extract a tooth from a man' (far right).

"This drawing depicts the concept that if we could try to find a mechanical procedure with which to withdraw teeth, it would be painless. These kinds of nineteenth century mentalities and ideas came from progress and industrialisation, with steam power being at the forefront of these developments." 
However, he explains that the ideas behind the use of the machine itself surprisingly comes from an older invention.

"I think the idea of using a machine to lessen pain comes from the guillotine, which may sound more striking than it is. The guillotine was called the 'painless machine', the rationale being that the executioner was no longer needed and so everyone was equal in the eyes of the law. It followed that the pain would be essentially the same for all and therefore painless. It was not a subjective individual who was going to be given money to do the job, but simply an objective machine."

Though dentistry has come a long way from its origins with the introduction of modern anaesthetics and procedures, there are still many who dread a visit to the dentist. So why do some people go to the dentist with fear despite the fact that they may not feel much pain if anything at all when they are treated? Javier has some thought provoking answers. "If we talk about social fears of pain, dentistry is one of them mainly for two reasons," he asserts.

"One is because it is related to amputation, the fact that somebody is going to take a piece of you out. It is also because of historical and religious reasons. With dentistry in the middle ages in early modern Europe, tooth pulling was usually done in public, almost like a show. The dentist came into the town and whoever had to have their teeth pulled had it done in front of everybody else, because it was a sort of expiration, it was a necessary pain."

Javier continues, "There are also religious concerns on this too. According to the bible, Adam sinned by biting the apple, so the story goes that God punished both the sinner and the instrument by which he had committed that sin, so it was part of the expiration that we all should go through and a reminder that there were other torments awaiting us if we didn't behave." He adds that if we take these considerations together, we can understand the root of where some of the fears may come from. "I think the dentists are doing their job and they convince people that

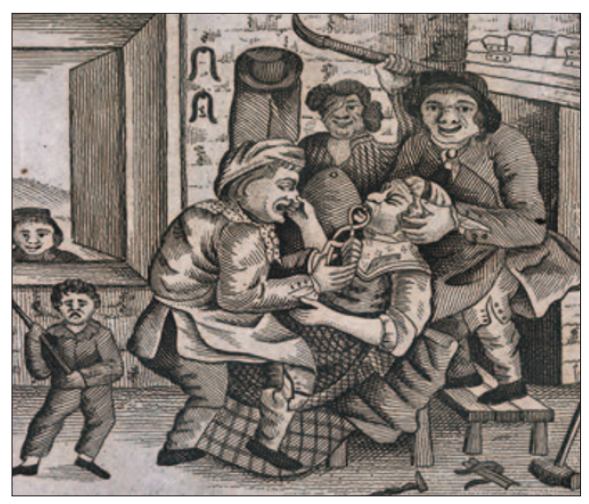

The Country Tooth Drawer (c. 1800) dental health is important, but of course history cannot be denied."

Ken Arnold, Head of Exhibitions at the Wellcome Trust has a different take on it. He says, "I think perhaps dentists administer physical treatment much more frequently than doctors for instance and this treatment, at least in the past, frequently did involve pain experienced in the dentist's surgery. Also, dentists are frequently associated with needles, which in some patients provokes a strong phobic response."

Javier explains that the concepts in the exhibition have come from the idea that pain is a very difficult subject as it involves many different possibilities. On the one hand we are a non-tolerant society towards pain but then at the same time we are pain consumers. "We go to the movies and see it in the media, we think it is perfectly alright to consume the pain of others," he explains.

"In the exhibition we simply tried to talk about pain from many different angles and what I think people find so interesting is that there are things in it that are so common, so 'everyday', well understood and accepted. However, taken in the context of an exhibition creates a different understanding of them, which is very fascinating."

Images courtesy of the Science Museum and the Wellcome Trust.

Pain: Passion, Compassion, Sensibility runs from 13 February - 20 June 2004, at the Science Museum, Exhibition Road, London. Admission is free, for information telephone 08708704868.

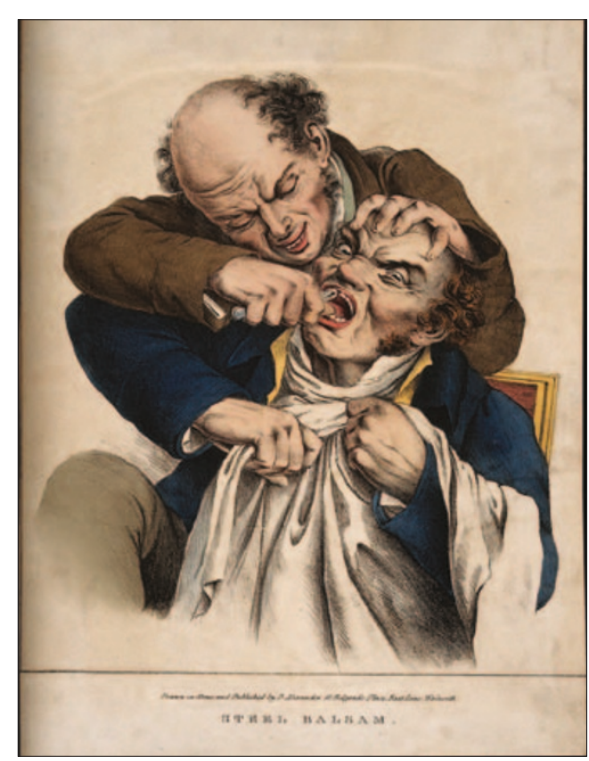

Grimaces, Louis Leopold Boilly (1823-28)

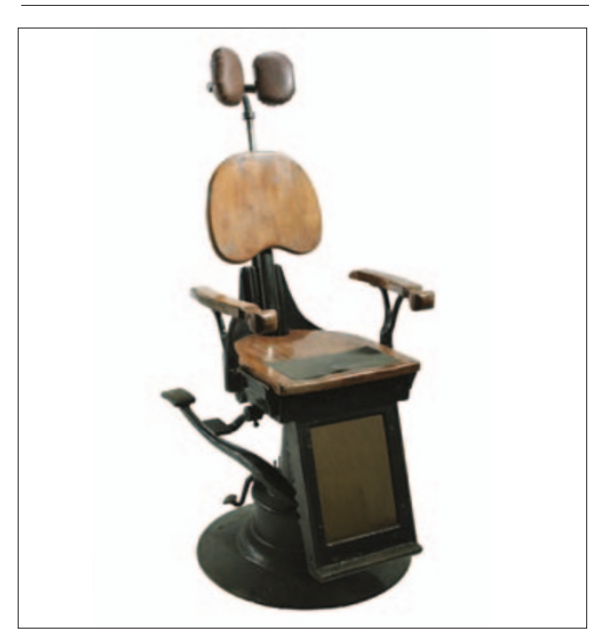

Child's dental chair, cast iron with mahogany fittings by the Dental Manufacturing Co. England (1910-30)

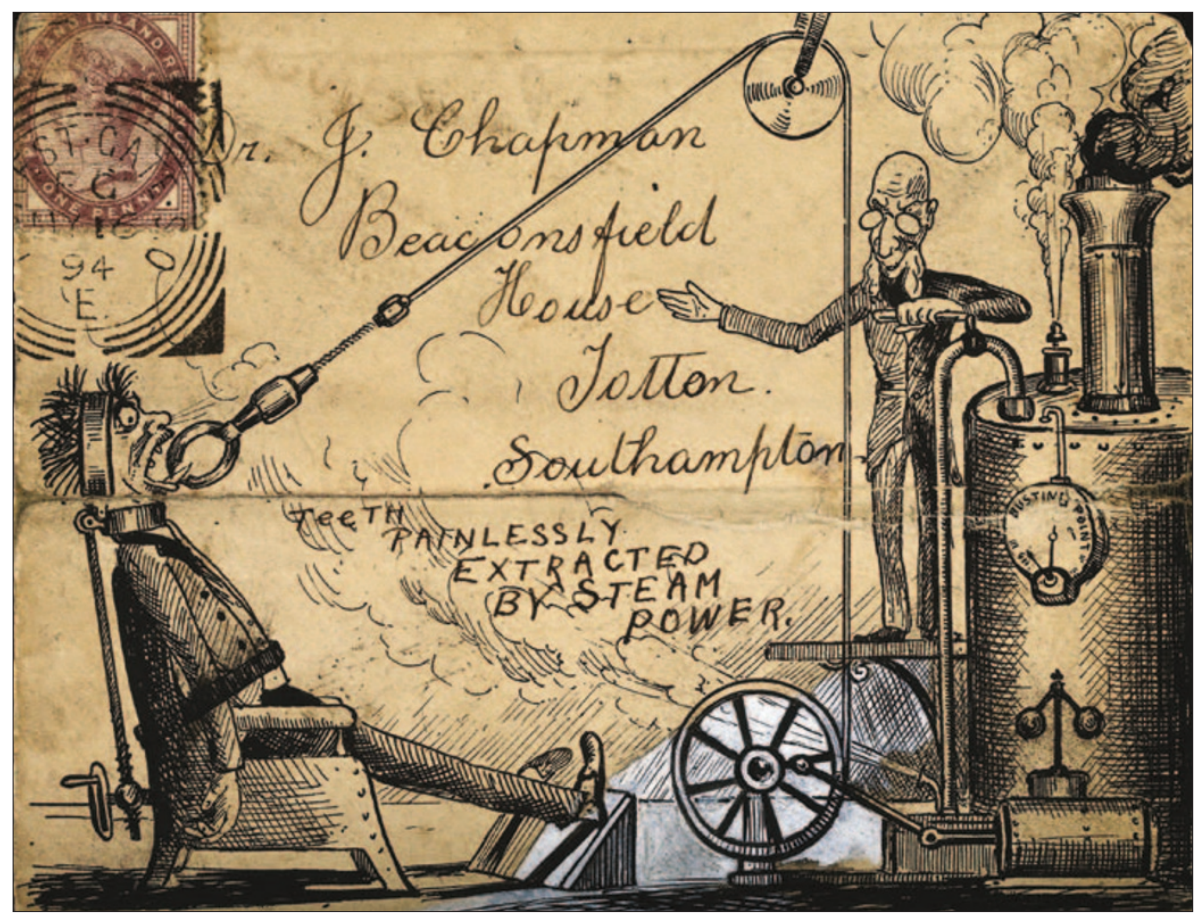

A scientist using a steam machine with pulley to extract a tooth from a man (1894) 